\title{
PERSPECTIVE
}

\section{Two Ideas To Increase Innovation And Reduce Pharmaceutical Costs And Prices}

\author{
What policy proposals can be made to best increase current \\ consumer welfare while maintaining or increasing incentives to \\ innovate?
}

\section{by Arjun Jayadev and Joseph Stiglitz}

ABSTRACT: The pharmaceutical industry is undergoing a period of uncertainty. Profits are being squeezed by increasing costs and competitive pressures, and new drug production is slowing down. This Perspective reviews two policies that could assist in realigning incentives toward genuine innovation while also keeping drug spending growth under check. Value-based pricing can incentivize genuinely new discoveries and align research and development with social welfare. Public funding of clinical trials likewise can reduce both pharmaceutical costs and prices and direct research effort in a manner that is more socially productive than the current state of affairs. [Health Affairs 28, no. 1 (2009): w165w168 (published online 16 December 2008; 10.1377/hlthaff.28.1.w165)]

A PERIOD OF TURMOIL is imminent for the pharmaceutical industry. The -pipeline of new drugs appears to be slowing down, increased generic competition is imminent in several key segments where "blockbuster drugs" are concentrated, and insurers and payers are looking more aggressively for cheaper alternatives. ${ }^{1}$ In addition, existing pharmaceutical regulations on prices such as price controls and reference pricing reduce revenues to pharmaceutical companies, and there is increasing pressure to reduce prices through regulation in the United States. ${ }^{2}$ This confluence of events will mean significant changes in the industry's structure. Further, the squeeze on profits, it is argued, could have adverse impacts by reducing innovation incentives, and thereby could lower worldwide access to novel treatments in the future.

Given these facts, what policy proposals can be made that will best increase current consumer welfare while simultaneously maintaining or increasing incentives to innovate? We here proffer two proposals that should be considered: (1) replacing existing priceregulatory structures with a value-based approach to pricing; and (2) moving toward public funding of clinical trials. The former can serve to realign national regulators' budgetary allocations in a non-arbitrary fashion to maximize access to innovative drugs. The latter could simultaneously direct research into more productive areas and reduce the cost of drug development, while having a number of potential ancillary benefits.

Arjun Jayadev (arjun.jayadev@umb.edu) is an assistant professor of economics at the University of Massachusetts Boston and a fellow at the Committee on Global Thought, Columbia University, in New York City. Joseph Stiglitz is a University Professor at Columbia University. He won the Nobel Prize in economics in 2001.

HEALTH AFFAIRS - Web Exclusive 
Any reward structure should balance the (expected) marginal benefit of directing innovation at a particular product with its marginal cost. From a social viewpoint, the "innovative" content of a discovery should reflect not simply whether it is nonobvious (and so eligible for patent protection) but whether it affords significant additional clinical benefits. (One of the weaknesses of the empirical literature is that all new chemical entities, or NCEs, are often treated as innovations.) For example, it is now well recognized that there is broad substitutability between competing brands of statins, except at high doses. The large market for these drugs in the United States and elsewhere, and the relative ease of patenting these in novations, means that there is continued social inefficiency in terms of expended research effort as pharmaceutical com-

"A truly innovative
drug may have its
profitability
destroyed by even an
inferior 'me-too' drug
from a company that
does a better job of
marketing."

ready been recognized in different contexts. The Office of Fair Trading in the United Kingdom, for example, has proposed that the country replace profit and price controls with a value-based approach to pricing, which would work to relate the spending for drugs to their incremental clinical and therapeutic value to patients and the broader National Health Service (NHS). Specifically, this policy involves assessing the marginal clinical benefit of additional drugs through the impact on qualityadjusted life-years (QALYs). ${ }^{5}$ Such a policy also has the advantage of reducing the arbitrariness of profit controls. Although it will reduce incentives for "me-too" drugs, it will increase incentives for more-fundamental innovations, reducing the uncertainty of the ability to appropriate returns. Currently, a truly innovative drug may panies direct research into drugs that are similar to existing products. Such drugs sometimes do have some increased therapeutic value (even "me-too" drugs may have slightly different side effects for some patients) and may provide an additional contribution to consumer welfare through product competition. ${ }^{3}$ However, it would be difficult to claim that the marginal social benefit from these drugs equals the marginal cost of innovation. Estimates of total research on standard drugs suggest that these costs constitute 80 percent of research and development (R\&D) expenditure. $^{4}$

Use a value-based approach to pricing. Given this social inefficiency, there may be the potential to have well-worked-out regulations that aid in reducing costs to consumers but also provide reasonable and directed incentives for research-based pharma. In those countries where purchase price can be determined by government entities, linking the price that regulators are willing to pay to a metric of additional value will reduce incentives to provide innovations of marginal benefit, including "me-too" products. This has al- have its profitability destroyed by even an inferior "me-too" drug from a pharmaceutical company that does a better job of marketing.

- Public funding of clinical trials. There are other significant problems in ensuring that scarce research dollars are allocated in ways that maximize social returns to innovation. Perhaps the most significant is the growing cost of drug development and, in particular, the cost of clinical trials. One often-cited (but still controversial) set of estimates suggests that the average costs of trials is on the order of $\$ 400$ million per NCE, a large fraction of total developmental costs. ${ }^{6}$ Accordingly, rethinking policy for clinical trials may be one of the simplest and most effective policy changes to increase efficiency in drug innovation. Particularly promising are proposals to publicly fund clinical trials for pharmaceuticals. In the recent past there have been several calls for an increase in public oversight and funding of clinical trials for prescription drugs. ${ }^{7}$ Dean Baker's comprehensive proposal involves federal contracting with private-sector firms, which choose to conduct trials based on preclinical results reported by innovators. (Alter- 
natively, testing could be done in house through the National Institutes of Health or the Food and Drug Administration.) The costs for these trials could be recovered as part of the charges imposed on the sale of drugs. Overall drug prices should be lower, as a result of the considerable savings from implementing such a policy.

There are two fundamental arguments in favor of this approach: First, clinical trials should rightly be seen as a public good. Information flowing out of clinical trials, once publicly available, could improve the decision making in R\&D as pharmaceutical firms choose better candidates for testing from their libraries. This transparency might even include open access to data, which would be made publicly available in the same way in which the government promotes the

\begin{tabular}{|} 
"Given the current \\
state of the industry, \\
different ideas will \\
need to be \\
considered as the \\
sector finds \\
alternative business \\
models."
\end{tabular}

not only raises costs, but also reduces competition. Doctors participating in trials are more likely to prescribe the drugs once they are certified; given the high switching costs (and the fact that patients typically bear a small fraction of the overall costs), this reduces the effective elasticity of demand. Reduced competition, in turn, results in higher prices and greater rent-seeking expenditures (including on advertising and marketing).

Public funding of clinical trials provides other advantages for advancing innovation and reducing costs. The costs of clinical trials serve as a major entry barrier, reducing competition and raising prices. They also discourage drug companies from engaging in research in particular products; if companies did not have to defray the costs of clinical trials, there would be a lower threshold of availability of census and Current Population Survey data. Such access would obviate costly duplicative R\&D and would increase oversight, as anyone anywhere in the world could evaluate the outcomes against whatever baseline characteristics they choose.

Currently, drug companies have been pushing for more-restrictive use of data generated by testing, which could reduce access to medicines, especially in third-world countries. Several recent bilateral trade agreements have provisions on data exclusivity that act as an extra layer of protection over and above the patent, without clear social benefits.

Greater confidence in the quality of testing is a second major argument in favor of public testing. Public funding of trials can reduce conflicts of interest, whose consequences have been evident in several recent scandals in which drug companies seem to have suppressed relevant evidence on safety and efficacy.

These conflicts of interest contribute to the high costs of testing - and even to the high costs of drugs. The implicit or explicit bribing of doctors involved in clinical trials research required revenues to make $R \& D$ worthwhile. As such, there would potentially be profitable opportunities across a much wider range of products. Second, with appropriate guidelines that mandate testing against existing drugs and encourage contracting firms to undertake trials that improve public health, public financing could disincentivize "me-too" drugs. Under the current system, "me-too" drugs whose social benefits are unlikely to match the testing costs are tested nonetheless-all the drug companies care about is whether they will be able to appropriate enough of the existing market to compensate for the incremental testing costs. But under public financing (in which the government uses an expected valuebased approach) in which there is an arm'slength relationship between the contracting firm and the pharmaceutical company, there is little incentive for the firm to undertake such trials.

Moreover, larger pharma firms have an implicit advantage in conducting trials because they are able to use their deep pockets to diversify risk. As such, they are in an advantageous position in relation to their biotechnology 
counterparts and other smaller firms that are in R\&D partnerships. Smaller biotech companies and others seeking to maintain control over their innovation may be better incentivized and more secure against takeover if they are able to concentrate on innovation and not rely on larger partners to bring their output to market. The diseconomies of scope (combining testing, innovation, and marketing) undermine principles of comparative advantage and are likely to overwhelm whatever economies of scope may exist.

- Concluding comments. Given the current state of the industry, and the general erosion of trust in its innovative capacity and its testing, different ideas will need to be considered as the sector finds alternative business models. In general, proposals are hard to come by. These two ideas can simultaneously serve the multiple goals of reducing costs, reducing prices, increasing the overall pace of innovation, and directing more innovation to areas for which social returns are highest.

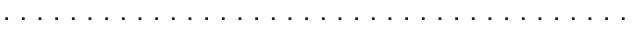
Joseph Stiglitz acknowledges funding from the Hewlett and Ford Foundations and the Rockefeller Brothers Fund. The authors thank Dean Baker for useful conversations (with the usual caveats).

\section{NOTES}

1. E. Berndt and D. Cutler, "Prescription Drug Spending Trends in the United States: Looking beyond the Turning Point," Health Affairs 28, no. 1 (2009): w151-wl60 (published online 16 December 2008; 10.1377/hlthaff.28.l.w15l).

2. N. Sood et al., "The Effect of Regulation on Pharmaceutical Revenues: Experience in Nineteen Countries," Health Affairs 28, no. 1 (2009): wl25wl37 (published online 16 December 2008; 10.1377/hlthaff.28.1.w125); and D.N. Lakdwalla et al., "U.S. Pharmaceutical Policy in a Global Marketplace," Health Affairs 28, no. 1 (2009): wl38wl50 (published online 16 December 2008; 10.1377/hlthaff.28.1.w138).

3. F. Lichtenberg and T. Philipson, "The Dual Effects of Intellectual Property Regulations: Within-and Between-Patent Competition in the U.S. Pharmaceuticals Industry," Journal of Law and Economics 45, no. 2 (2002): 643-672.

4. D. Baker, "The Benefits and Savings of PubliclyFunded Clinical Trials of Prescription Drugs,"
Center for Economic Policy and Research Working Paper, March 2008, http://www.cepr.net/ index.php/publications/reports/the-benefitsand-savings-of-publicly-funded-clinical-trialsof-prescription-drugs (accessed 24 November 2008).

5. K. Claxton et al., "Value Based Pricing for NHS Drugs: An Opportunity Not to Be Missed?" BMJ 336, no. 7641 (2008): 251-254.

6. J.A. DiMasi, R.W. Hansen, and H.G. Grabowski, "The Price of Innovation: New Estimates of Drug Development Costs," Journal of Health Economics 22, no. 2 (2003): 151-185.

7. T. Lewis, J. Reichman, and A. So, "The Case for Public Funding and Public Oversight of Clinical Trials," Economists' Voice 4, no. 1 (2007); and Baker, "The Benefits and Savings." 
Copyright of Health Affairs is the property of Project HOPE/HEALTH AFFAIRS and its content may not be copied or emailed to multiple sites or posted to a listserv without the copyright holder's express written permission. However, users may print, download, or email articles for individual use. 